\title{
Suppressive Effects of the Leaf of Terminalia catappa L. on Osteoclast Differentiation In Vitro and Bone Weight Loss In Vivo
}

\author{
Tomoyuki Koyama ${ }^{1}$, Chie NAKAJIMA ${ }^{1}$, Sogo Nishimoto ${ }^{1}$, Masamichi TAKAMI $^{2}$, \\ Je-Tae WOO $^{3}$ and Kazunaga YAZAWA ${ }^{1}$ \\ ${ }^{1}$ Laboratory of Nutraceuticals and Functional Foods Science, Graduate School of Marine Science and Technology, \\ Tokyo University of Marine Science and Technology, 4-5-7 Konan, Minato-ku, Tokyo 108-8477, Japan \\ ${ }^{2}$ Department of Biochemistry, School of Dentistry, Showa University, Tokyo 142-8555, Japan \\ ${ }^{3}$ Department of Biological Chemistry, Chubu University, Aichi 487-8501, Japan
}

(Received July 27, 2011)

\begin{abstract}
Summary Oral administration of Terminalia catappa extract (TCE; 1,000 mg/kg) for $5 \mathrm{wk}$ suppressed bone weight loss and trabecular bone loss in ovariectomized mice. An in vitro experiment showed that TCE $(1.3-20 \mu \mathrm{g} / \mathrm{mL})$ did not increase alkaline phosphatase activity, which would indicate osteoclast formation, in osteoblast-like 3T3-L1 cells. On the other hand, TCE $(12.5 \mu \mathrm{g} / \mathrm{mL})$ markedly decreased the number of tartrate resistant acid phosphatase (TRAP)-positive multinucleated cells, which would indicate osteoclast formation, in a co-culture system (bone marrow cells/osteoblastic UAMS-32 cells). A detailed analysis of the stages of osteoclast differentiation revealed that TCE mainly suppressed the differentiation of bone marrow mononuclear cells into osteoclast progenitor cells in the presence of MCSF and TGF- $\beta$. An additional experiment using fractionated TCE revealed that the watersoluble fraction suppressed the bone weight loss in OVX-mice and osteoclast differentiation in vitro. Therefore, the suppressive effects of TCE on bone weight loss in mice might be due to the suppressive effects of highly polar components on the early stage of osteoclast differentiation.
\end{abstract}

Key Words leaf of Terminalia catappa, prevention of osteoporosis, bone weight loss, osteoclast differentiation, ovariectomized mice

Imbalances in bone remodeling that are caused by an increase in bone resorption relative to bone formation are the cause of most adult skeletal diseases, including osteoporosis and rheumatoid arthritis (1). Estrogen deficiency leads to the most common form of osteoporosis in postmenopausal women. Estrogen replacement therapy is approved for the prevention of bone loss in postmenopausal women as an effective treatment for reducing the incidence of skeletal fractures. However, estrogen usage and compliance are limited due to its numerous undesirable side effects. Therefore, it would be helpful to explore naturally occurring substances, especially those of plant origin that could prevent bone loss without any adverse effects.

In our preliminary study to regulate bone remodeling, Terminalia catappa was shown to have suppressive effects against bone weight loss in ovariectomized mice

\footnotetext{
E-mail: tskoyama@kaiyodai.ac.jp

Abbreviations: ALP, alkaline phosphatase; AP-1, activator protein 1; BMP-2, bone morphogenetic protein 2; FBS, fetal bovine serum; JNK, c-Jun $N$-terminal kinase; MAPK, mitogenactivated protein kinase; M-CSF, macrophage colony stimulating factor; $\alpha$-MEM, $\alpha$-minimum essential medium; MTT, 3(4,5-dimethylthiazol-2-yl)-2,5-diphenyltetrazolium bromide; $1,25(\mathrm{OH})_{2} \mathrm{VD}_{3}, 1 \alpha, 25$-dihydroxyvitamin $\mathrm{D}_{3}$; OVX, ovariectomy; $\mathrm{PGE}_{2}$, prostaglandin $\mathrm{E}_{2}$; RANKL, receptor activator of nuclear factor- $\kappa \mathrm{B}$ ligand; TGF- $\beta$, transforming growth factor- $\beta$; TRAP, tartrate-resistant acid phosphatase.
}

(unpublished data). The leaves have been used as a folk medicine for treating dermatitis and hepatitis in Asian countries (2). In Taiwan, the fallen leaves of T. catappa have been used to prevent hepatoma and to treat hepatitis, both after drying and shredding and as a drink made by infusion in hot water (3). Some previous studies showed that water extracts of T. catappa leaves could effectively suppress $\mathrm{CCl}_{4}$-induced hepatotoxicity $(2,4)$ and bleomycin-induced genotoxicity in Chinese hamster ovary cells (3). It has also been reported that the extract of T. catappa leaves shows both antioxidative (5) and anti-inflammatory (6) effects. However, there has been no report of a suppressive effect of T. catappa leaf extract on bone resorption. Therefore, we evaluated the effects of an extract of T. catappa leaves in both in vivo and in vitro experiments.

\section{MATERIALS AND METHODS}

Preparation of extract. Terminalia catappa L. leaves were collected in the Kanto area in Japan. Leaves were dried at $70^{\circ} \mathrm{C}$ for $24 \mathrm{~h}$, and then cut and extracted with boiled water for $1 \mathrm{~h}$. After filtration, the extract was freeze-dried and stored at $-20^{\circ} \mathrm{C}$. The dried extract was resolved in sterilized and distilled water before being used as a crude extract for in vitro and in vivo experiments.

Evaluation of bone weight loss in ovariectomized mice. Four-week-old female ddY mice (Japan SLC, Inc., Shi- 
zuoka, Japan) were divided into groups (8 mice each). Mice were anesthetized with pentobarbital and subjected to ovariectomy or sham operation. Oral administration of the vehicle or TCE dissolved in distilled water was started from the day after surgery and continued at $5 \mathrm{~d}$ per week for $5 \mathrm{wk}$ under conditions of $24 \pm 1^{\circ} \mathrm{C}$ and $50 \pm 2 \%$ humidity with a $12 \mathrm{~h}$ light-dark cycle (light on from 8:00 to 20:00). Finally, mice were sacrificed so that their femurs could be extracted (7). The right femurs were used to measure dry weight (dried at $60^{\circ} \mathrm{C}$ for $24 \mathrm{~h}$ ) and the dried femurs were ground from the backside using a fine grindstone. The ground femurs were then washed with water, ethanol, and bleaching solution containing $0.5 \%$ sodium hypochlorite. The femurs were dried again and observed using a microscope. The amount of cancellous bone was measured on a photograph of the ground bone. All animal studies were performed in compliance with the 2006 guidelines entitled "Notification No. 88 of the Ministry of the Environment in Japan".

Cell culture method. All cell cultures were maintained at $37^{\circ} \mathrm{C}$ in a humidified atmosphere containing $5 \% \mathrm{CO}_{2}$ in air. Half of the medium was changed every 3 d. Cell viability was evaluated using a 3-(4,5-dimethylthiazol-2-yl)-2,5-diphenyl tetrazolium bromide (MTT, Sigma-Aldrich Chemical Co., St. Louis, MO) assay. After culture, cells were treated with $1 \mathrm{mg} / \mathrm{mL}$ MTT for $2 \mathrm{~h}$, the precipitated dye was dissolved in dimethylsulfoxide, and the absorbance at $570 \mathrm{~nm}$ was measured.

Alkaline phosphatase (ALP) activity in osteoblast cells (8). Osteoblast-like MC3T3-E1 cells (Riken Bioresource Center, Ibaraki, Japan) were cultured in $\alpha$-minimum essential medium ( $\alpha$-MEM, MP Biomedicals, Eschwege, Germany) for the measurement of ALP activity, which was used as an indicator of osteoblast formation $(n=3)$. The cells were seeded at a concentration of $4 \times 10^{5}$ cells/well on 96 -well micro plates with or without TCE (1.3-20 $\mu \mathrm{g} / \mathrm{mL})$. ALP activity was measured using an ALP LabAssay kit 291-58601 (Wako Pure Chemical Industries, Ltd., Osaka, Japan). Bone morphogenetic protein 2 (BMP-2) (9), which was used as a positive control in the assay, was purchased from Wako Pure Chemical Industries, Ltd.

Assay of osteoclast formation in a co-culture system (10). The effects of T. catappa extract (TCE) on osteoclast formation were examined in a co-culture system that included osteoblastic UAMS-32 cells $(11)\left(5 \times 10^{4}\right.$ cells $/ \mathrm{mL})$ and bone marrow cells $\left(1 \times 10^{6}\right.$ cells $\left./ \mathrm{mL}\right)$ isolated from murine tissues in $\alpha$-MEM containing $10 \%$ FBS in 96-well plates (Corning Inc., Corning, NY). The culture volume was made up to $200 \mu \mathrm{L}$ per well with $\alpha$ MEM supplemented with $10 \%$ FBS, in the presence of $4.1 \mathrm{ng} / \mathrm{mL} 1 \alpha, 25(\mathrm{OH})_{2} \mathrm{VD}_{3}$ (Enzo Life Sciences International Inc., Butler Pike, PA) and $352.5 \mathrm{ng} / \mathrm{mL} \mathrm{PGE} 2$ (Cayman Chemical, Ann Arbor, MI), with or without TCE. Murine femoral and tibial bone marrow cells were collected from 8-wk-old mice that had been killed by cervical dislocation (12).

Osteoclast formation in the absence of osteoblast cells (13). To investigate the effects of TCE on the differenti- ation of osteoclast cells, bone marrow cells $\left(1 \times 10^{6}\right.$ cells $/ \mathrm{mL}$ ) were differentiated with two stimulating steps in the absence of osteoblast cells. In the first step, bone marrow cells differentiated to osteoclast progenitor cells after $3 \mathrm{~d}$ of incubation in the presence of $50 \mathrm{ng} / \mathrm{mL}$ of macrophage colony stimulating factor (M-CSF, R\&D Systems Inc., Minneapolis, MN) and $1 \mathrm{ng} / \mathrm{mL}$ transforming growth factor- $\beta$ (TGF- $\beta$, BD Bioscience, NJ). In the second step, osteoclast progenitor cells were cultured for $2 \mathrm{~d}$ with $50 \mathrm{ng} / \mathrm{mL} \mathrm{M}-\mathrm{CSF}$ and $50 \mathrm{ng} / \mathrm{mL}$ of the receptor activator of nuclear factor- $\kappa \mathrm{B}$ ligand (RANKL; Wako Pure Chemical Industries, Ltd.) to give pre-osteoclasts. Mature osteoclasts should be formed by the continued culture of pre-osteoclasts. We examined both steps in osteoclast formation with or without TCE.

Tartrate resistant acid phosphatase (TRAP) staining. After osteoclast formation, adherent cells were fixed with $10 \%$ formaldehyde in phosphate-buffered saline (-) for 20 min. After treatment with $95 \%$ ethanol for $1 \mathrm{~min}$, the well surface was dried and treated with TRAP staining solution (14), i.e. $0.1 \mathrm{~m}$ sodium acetate buffer ( $\mathrm{pH}$ 5.0) containing $50 \mathrm{~mm}$ sodium tartrate, $0.1 \mathrm{mg} / \mathrm{mL}$ naphthol AS-MX phosphate (Sigma-Aldrich Chemical Co.), and $1 \mathrm{mg} / \mathrm{mL}$ fast red violet $\mathrm{LB}$ salt (Sigma-Aldrich Chemical Co.), for $30 \mathrm{~min}$. TRAP-positive multinucleated cells were then counted as osteoclast cells under a microscope.

Fractionation of TCE. To identify the active constituents in the crude extract (TCE), an in vivo evaluation of activity was performed following fractionation. TCE $(15 \mathrm{~g})$ was partitioned between water and EtOAc $(1,000 \mathrm{~mL}$ each) three times. Each fraction was then dried and further partitioned to give four fractions, i.e., Hex fraction, $90 \%$ aqueous $\mathrm{MeOH}$ fraction, $\mathrm{BuOH}$ frac-

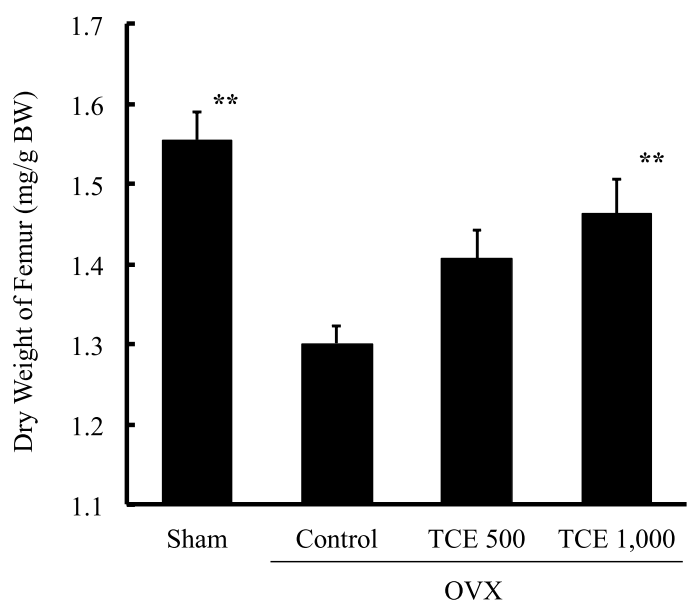

Fig. 1. Effect of TCE on femoral weight in ovariectomized mice. The body weights and dry weights of the femur were measured $5 \mathrm{wk}$ after the operations. Sham: sham-operated control given vehicle, OVX-Control: ovariectomized control given vehicle, OVX with TCE: ovariectomized and treated with Terminalia catappa extract (TCE; 500 and 1,000 mg/kg orally for $5 \mathrm{wk}$ ). Each bar is the mean \pm SE of 8 individuals. ${ }^{*} p<0.05,{ }^{* *} p<0.01$, $* * * p<0.001$, vs ovariectomized group treated with vehicle. 
A

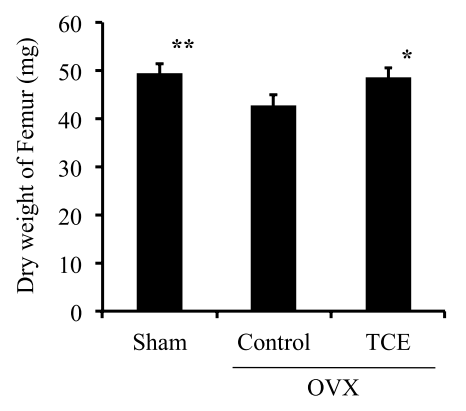

B

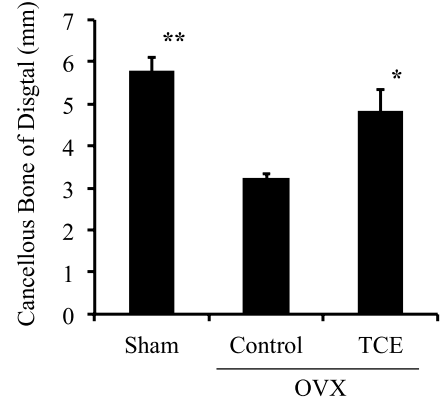

C

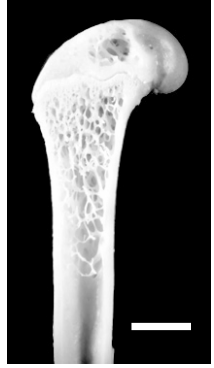

Sham

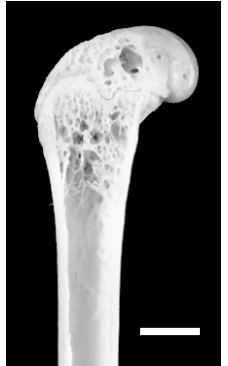

OVX

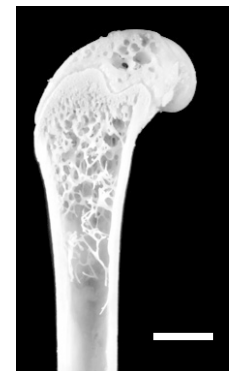

OVX + TCE

Fig. 2. Effects of TCE on the femoral weight (A), cancellous bone of the distal femur (B) and typical femoral morphology (C) in ovariectmized mice. TCE was administered orally for $5 \mathrm{wk}$. The length and dry weight of the femur were measured $5 \mathrm{wk}$ after the respective operations. The amount of cancellous bone was expressed as the distance from the primary spongiosa to the end of the substantia spongiosa. Sham: sham-operated control given vehicle, OVX-Control: ovariectmized control given vehicle, OVX with TCE: ovariectomized and treated with TCE $(500 \mathrm{mg} / \mathrm{kg}$ orally). Each point represents the mean \pm SE of 8 individuals. ${ }^{*} p<0.05,{ }^{* *} p<0.01,{ }^{* * *} p<0.001$ vs ovariectomized group treated with vehicle. Scale bar $=1 \mathrm{~mm}$.

Table 1. Effects of TCE on body weight and uterus weight in OVX mice.

\begin{tabular}{lllll}
\hline & & & \multicolumn{2}{c}{ OVX with TCE $(\mathrm{mg} / \mathrm{kg} / \mathrm{d})$} \\
\cline { 3 - 5 } & Sham & Control & 500 & 1,000 \\
\hline Initial BW (g) & $20.7 \pm 0.3$ & $20.4 \pm 0.3$ & $19.8 \pm 0.4$ & $19.9 \pm 0.3$ \\
Final BW (g) & $30.7 \pm 0.6$ & $31.7 \pm 0.9$ & $29.7 \pm 0.4$ & $30.2 \pm 1.0$ \\
Uterus weight (g/g BW) & $4.65 \pm 0.74^{* *}$ & $0.51 \pm 0.04$ & $0.54 \pm 0.03$ & $0.53 \pm 0.04$ \\
\hline
\end{tabular}

Experimental period is $4 \mathrm{wk}$ with ddY mice (female, $4 \mathrm{wk}$ ).

$* * * p<0.001$, vs ovariectomized control group without TCE.

tion and a water fraction. Each fraction (equivalent of $1,000 \mathrm{mg} / \mathrm{kg} \mathrm{TCE}$ ) was dried and dissolved in $1 \%$ aqueous ethanol for injection orally into OVX-treated mice.

Statistical analysis. Data were statistically analyzed using ANOVA followed by a Tukey-Kramer post-hoc analysis to determine the significance of differences in the data among the groups. $p$ values less than 0.05 were considered significant. The values are expressed as means \pm SE.

\section{RESULTS}

\section{Effects of TCE in ovariectomized mice}

The suppressive effects of TCE on bone resorption due to estrogen deficiency in the experimental animal model were examined. As shown in Fig. 1, TCE significantly prevented both the decrease in bone weight due to OVX and trabecular bone loss at $1,000 \mathrm{mg} / \mathrm{kg} / \mathrm{d}$. In the TCEtreated group $(500 \mathrm{mg} / \mathrm{kg} / \mathrm{d})$, bone morphology was observed with ground femurs. The average dry weight of femurs in the sham-operated group was $49.3 \pm$ $0.7 \mathrm{mg}$, while that in the ovariectomized group was $42.9 \pm 0.7 \mathrm{mg}$. This decrease in bone weight is thought to be the result of bone resorption enhanced by estrogen deficiency (Fig. 2A). Ovariectomy caused a decrease in the spongiosa of the distal femur. TCE significantly suppressed this decrease at a dose of $500 \mathrm{mg} / \mathrm{kg}$ (Fig. 2B and $\mathrm{C}$ ). On the other hand, TCE did not significantly affect body weight or uterine weight in mice, as shown in Table 1.

Effects of TCE on ALP activity in osteoblast cells

To evaluate the effects of TCE on osteoblastic MC3T3E1 cells, ALP activity in the medium was measured. Following incubation for $24 \mathrm{~h}$, the control group showed ALP activity of 19.9 units/mL. In the presence of BMP$2(50 \mathrm{ng} / \mathrm{mL})$, ALP activity was increased to $154.5 \pm$ $6.4 \%$ of that in the control. On the other hand, TCE did not produce a significant change in ALP activity $(71.3 \pm 4.9 \%$ of that in the control) even at $20 \mu \mathrm{g} / \mathrm{mL}$. 


\section{Effects of TCE on osteoclast formation}

Osteoclast differentiation was estimated by $\operatorname{TRAP}(+)$ multinucleated cell formation in UAMS-32 cell/bone marrow cell co-culture. Osteoclast formation was induced by the presence of $1 \alpha, 25(\mathrm{OH})_{2} \mathrm{VD}_{3}$ and $\mathrm{PGE}_{2}$ in the co-culture. When we did not add $1 \alpha, 25(\mathrm{OH})_{2} \mathrm{VD}_{3}$ and $\mathrm{PGE}_{2}$, osteoclast formation was not observed. However, when we added $1 \alpha, 25(\mathrm{OH})_{2} \mathrm{VD}_{3}$ and $\mathrm{PGE}_{2}$, osteoclast formation was noted. With the addition of TCE at $12.5,25$ and $50 \mathrm{mg} / \mathrm{mL}$, osteoclast formation and growth were significantly inhibited (Fig. 3). The number of differentiated osteoclasts induced by $1 \alpha, 25(\mathrm{OH})_{2} \mathrm{VD}_{3}$ and $\mathrm{PGE}_{2}$ was $296.3 \pm 34.7$ cells/well. The addition of TCE reduced the number of TRAP $(+)$ multinucleated cells, without cytotoxicity, to $14.1 \pm$ $6.4 \%$ at $12.5 \mathrm{mg} / \mathrm{mL}, 11.3 \pm 1.8 \%$ at $25 \mathrm{mg} / \mathrm{mL}$ and $10.3 \pm 4.4 \%$ at $50 \mathrm{mg} / \mathrm{mL}$.

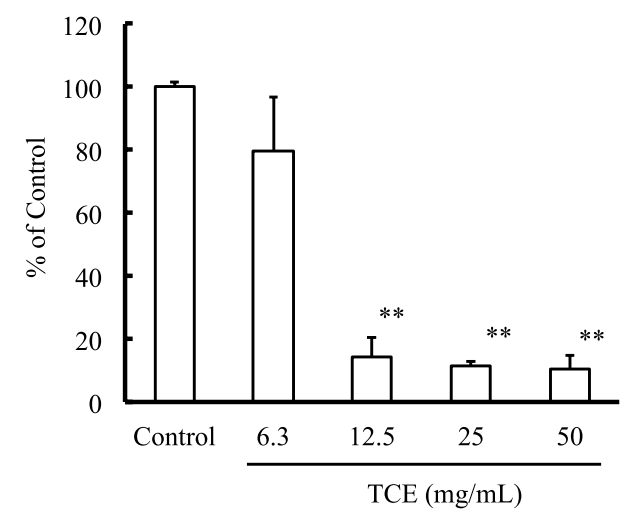

Fig. 3. Inhibition of osteoclast formation by TCE. TCE was added to a UAMS- 32 cell and bone marrow co-culture with $1 \alpha, 25(\mathrm{OH})_{2} \mathrm{VD}_{3}$ and $\mathrm{PGE}_{2}$ in 96-well plates. After incubation for $6 \mathrm{~d}$, cells were stained using the TRAP staining method. TRAP-positive multinucleated cells that had more than three nuclei were counted. Data are the mean \pm SE of four cultures. ${ }^{* * *} p<0.001 v s$ control.

\section{Effects of TCE on steps of osteoclast differentiation}

The suppressive effects of TCE on the two steps of osteoclast formation were examined. Bone marrow cells differentiated into osteoclast progenitor cells in the presence of TGF- $\beta$ and M-CSF (step 1). The cells then differentiated into pre-osteoclasts by stimulation with RANKL and M-CSF (step 2). When TCE was added at 6.3, 12.5 and $25 \mathrm{mg} / \mathrm{mL}$ to cultured bone marrow cells in the presence of TGF- $\beta$ and M-CSF (step 1), osteoclast formation was significantly suppressed (Fig. 4A). Furthermore, when TCE was added to cultured cells in the presence of RANKL and M-CSF (step 2), osteoclast formation was significantly suppressed (Fig. 4B).

Cytotoxicity of TCE

In all of the experiments using osteoblast and osteoclast cells, TCE (less than $25 \mu \mathrm{g} / \mathrm{mL}$ ) did not affect cell viability in the MTT assay.

Effects of TCE fractions on ovariectomized mice and osteoclast differentiation

Fractionation of TCE gave four fractions: a Hex fraction $(0.02 \mathrm{~g}, 0.15 \%), 90 \% \mathrm{MeOH}$ fraction $(0.79 \mathrm{~g}$, $5.55 \%), \mathrm{BuOH}$ fraction $(4.81 \mathrm{~g}, 30.8 \%)$ and a water fraction $(8.61 \mathrm{~g}, 60.1 \%)$. The suppressive effects of TCE $(1,000 \mathrm{mg} / \mathrm{kg})$ on bone weight loss were evaluated in ovariectomized mice. As shown in Fig. 5, the dry weight of femur in the OVX-control group was significantly decreased compared with that in the Sham group for $5 \mathrm{wk}$. On the other hand, treatment with the water fraction of TCE suppressed this decrease in bone weight. Treatment with the other fractions did not show any significant changes relative to the OVX-control group. The water fraction of TCE had a suppressive effect on osteoclast differentiation to $43.5 \pm 2.5 \%$ of that in the control at $25 \mu \mathrm{g} / \mathrm{mL}$ without cytotoxicity in an osteoclast formation test in the co-culture system. Since only the water fraction suppressed bone weight loss in OVXtreated mice and osteoclast differentiation in the co-culture system, the water fraction was expected to contain
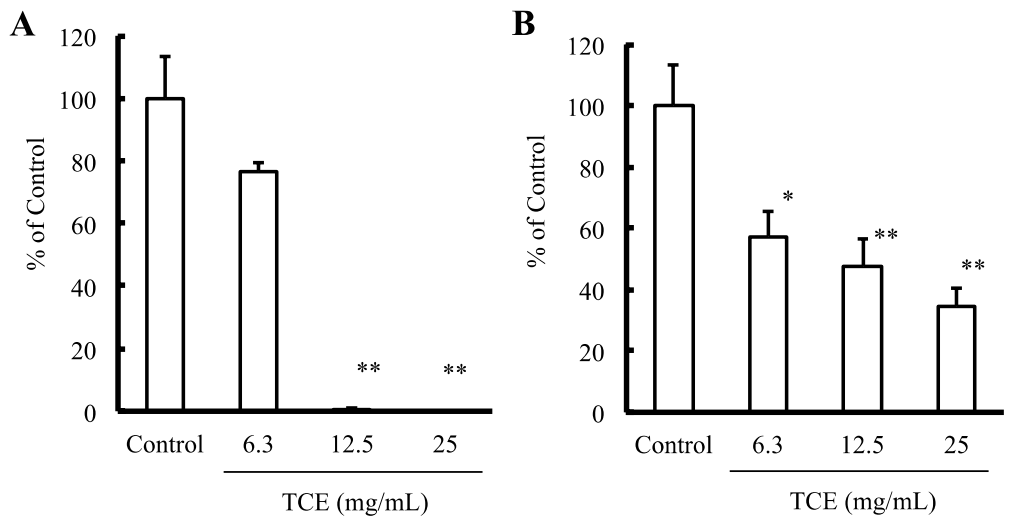

Fig. 4. Effects of TCE on osteoclast progenitor cells (A) and pre-osteoclasts (B) from bone marrow. Bone marrow cells were added to 96-well plates in $\alpha$-minimum essential medium ( $\alpha$-MEM) supplemented with $10 \%$ FBS containing macrophage colony-stimulating factor (M-CSF) and transforming growth factor- $\beta$ (TGF- $\beta$ ) for $3 \mathrm{~d}$ of incubation to prepare osteoclast progenitor cells. The resulting osteoclast progenitor cells were cultured for a further $2 \mathrm{~d}$ with M-CSF and receptor activator of nuclear factor- $\kappa \mathrm{B}$ ligand (RANKL). (A) Bone marrow cells were cultured with or without TCE in the presence of M-CSF and TGF- $\beta$ for $2 \mathrm{~d}$. (B) Osteoclast progenitor cells were cultured with or without TCE in the presence of M-CSF and RANKL for $3 \mathrm{~d}$. The number of osteoclasts in the control group was expressed as $100 \%$. TRAP-positive multinucleated cells that had more than three nuclei were counted. Data are the mean \pm SE of four cultures. ${ }^{* * *} p<0.001$ vs control. 


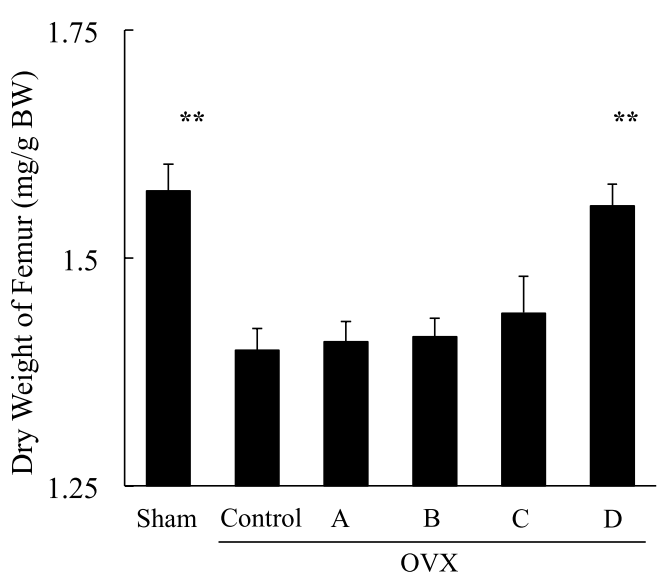

Fig. 5. Effects of fractions from TCE on the decrease in bone weight in OVX mice. Four-week-old female Std:ddY mice were ovariectomized and treated orally with sample solutions at $1,000 \mathrm{mg} / \mathrm{kg}$ (equivalent in TCE) $5 \mathrm{~d}$ per week for $5 \mathrm{wk}$. The femoral bone was then isolated and weighed. Each point represents the mean \pm SE $(n=6){ }^{* * *} p<0.001$ vs ovariectomized control. Sham: sham-operated control, OVX-Control: ovariectomized and treated with vehicle, OVX: ovariectomized and treated with different fractions-A: Hex fraction, $\mathrm{B}: 90 \% \mathrm{MeOH}$ fraction, $\mathrm{C}: \mathrm{BuOH}$ fraction, and D: water fraction.

the anti-osteoporotic component.

\section{DISCUSSION}

Bone is continuously shaped and repaired by bone remodeling, which consists of the processes of bone resorption by osteoclasts and bone formation by osteoblasts (2). Estrogen deficiency promotes bone resorption and trabecular bone becomes thin (15). We found that TCE inhibited bone resorption due to estrogen deficiency in this experimental animal model. The suppressive effects of TCE were seen at $1,000 \mathrm{mg} / \mathrm{kg}$ (Fig. 1), and significant suppression was not observed at a lower dose. As shown in Fig. 2, TCE significantly prevented the decrease in bone weight (panel A) and trabecular bone loss (panel B) due to OVX. The typical skeletal status of femoral bone is shown in panel C. Based solely on these results, the cause of the decrease in bone weight could not be estimated. Mineral components in the bone and bone density should be measured to clarify the detailed mechanisms in vivo in further experiments. Our present in vivo data demonstrated that TCE suppressed bone weight loss in OVX mice.

Based on these suppressive effects of TCE on bone weight loss in vivo, we anticipated that this extract either enhances bone formation or suppresses bone resorption. Alkaline phosphatase activity is a widely used marker of calcification and osteoblast maturation, both in vitro and in vivo (16). If this indicator is increased in the presence of TCE, we can assume that TCE has osteoblast-activating effects. However, treatment with TCE produced no significant difference in alkaline phosphatase activity compared with control levels in osteoblastic MC3T3-E1 cells. Next, we investi- gated the effect of TCE on osteoclast formation in a UAMS-32 cell/bone marrow cell co-culture. As shown in Fig. 3, TCE at more than $12.5 \mu \mathrm{g} / \mathrm{mL}$ suppressed osteoclast formation in a co-culture of bone marrow cells/osteoblasts. These results from in vitro experiments suggested that the suppressive effects of TCE on bone weight loss in vivo may have been due to the inhibition of bone resorption by osteoclasts rather than by the promotion of bone formation by osteoblasts. The results of our experiment could not exclude the possibility that TCE inhibited bone-marrow stromal cells, which support osteoclast differentiation (17) during incubation. To elucidate the detailed mechanisms in vitro, further investigations in a co-culture system without stromal cells, i.e., UAMS-32 and primary spleen cells, will be required.

In a co-culture system for osteoclast formation, osteoblast cells produce RANKL in response to a variety of signals such as $1 \alpha, 25(\mathrm{OH})_{2} \mathrm{VD}_{3}$ and parathyroid hormone. RANKL acts as a ligand for the receptor RANK on osteoclast progenitor cells to induce osteoclast differentiation. Since the amount of RANKL released in the co-cultured supernatant did not change in the presence of TCE (data not shown), TCE did not appear to suppress RANKL expression induced by $1 \alpha, 25(\mathrm{OH})_{2} \mathrm{VD}_{3}$ and $\mathrm{PGE}_{2}$ in vitro. These results show that TCE may suppress osteoclast formation through inhibition of either of the differentiation steps from bone marrow cells.

Moreover, we investigated the effect of TCE on osteoclast differentiation to determine the detailed mechanism of its suppressive effects on osteoclastogenesis. In the presence of M-CSF and TGF- $\beta$, bone marrow cells differentiate into osteoclast progenitor cells. In the presence of M-CSF and RANKL, these progenitor cells differentiate into pre-osteoclasts and mature. As shown in Fig. 4A and B, TCE markedly inhibited both of these steps in differentiation. The site of action of TCE was estimated to be the early step in differentiation of bone marrow cells. For elucidating detailed mechanisms, a further analysis of differentiation markers such as Mac1 or F4/80 may be useful in the differentiation from bone marrow cells to monocytic precursors in the presence of IL-3 and M-CSF. Based on these results in vitro, the inhibitory effects of TCE on osteoclast formation are not likely to be due to the inhibition of M-CSF function or RANKL expression on osteoblast cells.

Estrogen or $1 \alpha, 25(\mathrm{OH})_{2} \mathrm{VD}_{3}$ suppresses bone loss to reduce the number of osteoclasts in the early stage before the expression of RANKL in vivo (18). Estrogen has been shown to inhibit osteoclast differentiation by binding to estrogen receptor (ER) in osteoclast or marrow cells in vitro (19). The mechanisms of action of TCE are thought to be similar to those of estrogen. However, since the uterus weight did not increase under treatment with TCE in ovariectomized mice, TCE is not likely to act as an agonist of ER or an estrogen promoter in vivo.

The suppressive effects of TCE on osteoclast formation are expected to be different from those of these other components. TCE reduced osteoclast differentiation in 
the differentiation stage with M-CSF and TGF- $\beta$. Osteoclasts are specialized cells derived from the macrophage hematopoietic lineage, and they undergo differentiation in co-cultures of bone marrow and stromal cells (20, 21). TCE suppressed the early stage of differentiation, in which bone marrow cells are stimulated by M-CSF. Accordingly, TCE should also be able to suppress their differentiation into macrophage. This effect of TCE may be able to influence not only osteoporosis but also various immunologic diseases.

Various dietary components and herbal products have been reported to contain inhibitors of bone resorption. For example, it has been reported that onion, garlic and parsley can inhibit bone resorption in ovariectomized rats $(22,23)$. Quercetin from onion extract inhibits the differentiation of osteoclast progenitor into pre-osteoclasts and actin ring formation (24). Essential oils derived from rosemary, thyme and other herbs inhibit osteoclast activity in vitro (25). Ethanol extract from the Formosan orchid Anoectochilus formosanus suppressed bone loss caused by estrogen deficiency through the suppression of RANKL expression that is required for osteoclast formation (26). Hydrolysable tannins that were identified as the main components of TCE have been shown to regulate many biological activities, including antioxidative and antitumor activities $(27,28)$. Frosin, a hydrolysable ellagitannin, has been shown to inhibit both osteoclast differentiation and function through a mechanism that involves the inhibition of RANKL-induced p38 MAPK and JNK/AP-1 activation as well as actin ring formation (29).

On the other hand, experiments in vivo and in vitro using fractionated TCE revealed that a highly polar component from TCE suppressed bone weight loss in OVX mice and osteoclast formation in a co-culture cell system. The active principle in the water fraction of TCE remains to be elucidated. Further studies on TCE to elucidate the active component and its site(s) of action should promote its application as a new source of functional foods or as a medicine for preventing bone resorption.

In summary, Terminalia catappa extract was shown to suppress the decrease in bone weight caused by estrogen deficiency in mice. The extract was also shown to suppress osteoclast formation at the early stage. The water fraction of TCE showed suppressive activities both in vivo and in vitro. These results revealed that a highly polar component in TCE suppresses the decrease in bone weight in OVX-mice through the inhibition of osteoclast formation.

\section{Acknowledgments}

We gratefully thank Ms. Miyuki Shirosaki for collecting and preparing samples and the late Mr. Fumio Otsuki of Agriculture and Forest Promotion Public Co. of Ibaraki Prefecture for his kindness in giving advice and assistance which was critical for our research.

\section{REFERENCES}

1) Boyle WJ, Simonet WS, Lacey DL. 2003. Osteoclast differentiation and activation. Nature 423: 337-342.

2) Lin CC, Kan WS. 1990. Medical plants used for the treatment of hepatitis in Taiwan. Am J Chin Med 18: 38-43.

3) Chen PS, Li JH, Liu TY, Lin TC. 2000. Folk medicine Terminalia catappa and its major tannin component, punicalagin, are effective against bleomycin-induced genotoxicity in Chinese hamster ovary cells. Cancer Lett $\mathbf{5 1 2}$ : 115-122.

4) Tang X, Gao J, Wang Y, Fan YM, Xu LZ, Zhao XN, Xu Q, Qian ZM. 2006. Effective protection of Terminalia catappa L. leaves from damage induced by carbon tetrachloride in liver mitochondria. J Nutr Biochem 17: 177182.

5) Kinoshita S, Inoue Y, Nakama S, Ichiba T, Aniya Y. 2007. Antioxidant and hepatoprotective actions of medicinal herb, Terminalia catappa L. from Okinawa Island and its tannin corilagin. Phytomedicine 14: 755762.

6) Lin CC, Hsu YF, Lin TC. 1999. Effects of punicalagin and punicalin on carrageenan-induced inflammation in rats. Am J Chin Med 27: 371-376.

7) Masuda K, Ikeuchi M, Koyama T, Yamaguchi K, Woo JT, Nishimura T, Yazawa K. 2008. Suppressive effects of Anoectochilus formosanus extract on osteoclast formation in vitro and bone resorption in vivo. J Bone Miner Metab 26: 123-129.

8) Yamamoto M, Takahashi Y, Tabata Y. 2003. Controlled release by biodegradable hydrogels enhances the ectopic bone formation of bone morphogenetic protein. Biomaterials 24: 4375-4383.

9) Fromigue O, Marie PJ, Lomri A. 1998. Bone morphogenetic protein-2 and transforming growth factor-beta2 interact to modulate human bone marrow stromal cell proliferation and differentiation. I Cell Biochem 68: 411-426.

10) Takami M, Woo JT, Nagai K. 1999. Osteoblastic cells induce fusion and activation of osteoclasts through a mechanism independent of macrophage-colony-stimulating factor production. Cell Tissue Res 298: 327-334.

11) Takami M, Cho ES, Lee SY, Kamijo R, Yim M. 2005. Phosphodiesterase inhibitors stimulate osteoclast formation via TRANCE/RANKL expression in osteoblasts: possible involvement of ERK and p38 MAPK pathways. FEBS Lett 579: 832-838.

12) Takahashi N, Yamana H, Yoshiki S, Roodman GD, Mundy GR, Jones SJ, Boyde A, Suda T. 1988. Osteoclastlike cell formation and its regulation by osteotropic hormones in mouse bone marrow cultures. Endocrinology 122: 1373-1382.

13) Quinn JMW, Whitty GA, Byrne RJ, Gillespie MT, Hamilton JA. 2002. The generation of highly enriched osteoclast-lineage cell populations. Bone 30: 164-170.

14) Burstone MS. 1959. Histochemical demonstration of acid phosphatase activity in osteoclasts. J Histochem Cytochem 7: 39-41.

15) Parfitt AM, Mathews CHE, Villanueva AR, Kleerekoper M. 1983. Relationships between surface, volume, and thickness of iliac trabecular bone in aging and osteoporosis. J Clin Invest 72: 1396-1409.

16) Zernik J, Twarog K, Upholt WB. 1990. Regulation of alkaline phosphatase and alpha2(I) procollagen synthe- 
sis during early intramembranous bone formation in the rat mandible. Differentiation 44: 207-215.

17) Kodama H, Nose M, Niida S, Yamasaki A. 1991. Essential role of macrophage colony-stimulating factor in the osteoclast differentiation supported by stromal cells. $J$ Exp Med 173: 1291-1294.

18) Nakamura T, Imai $Y$, Matsumoto T, Sato S, Takeuchi K, Igarashi K, Harada Y, Azuma Y, Krust A, Yamamoto Y, Nishina H, Takeda S, Takayanagi H, Metzger D, Kanno J, Takaoka K, Martin TJ, Chambon P, Kato S. 2007. Estrogen prevents bone loss via estrogen receptor alpha and induction of Fas ligand in osteoclasts. Cell 130: 811823.

19) Shibata T, Shira-ishi A, Sato T, Masaki T, Sasaki A, Masuda Y, Hishiya A, Ishikura N, Higashi S, Uchida Y, Saito M, Ito M, Ogata E, Watanabe K, Ikeda K. 2002. Vitamin D hormone inhibits osteoclastogenesis in vivo by decreasing the pool of osteoclast precursors in bone marrow. J Bone Miner Res 17: 622-629.

20) Baron R. 1989. Molecular mechanisms of bone resorption by the osteoclast. Anat Rec 224: 317-324.

21) Miura M, Tanaka K, Komatsu Y, Suda M, Yasuda A. 2002. A novel interaction between thyroid hormones and $1 \alpha, 25(\mathrm{OH})_{2} \mathrm{VD}_{3}$ in osteoclast formation. Biochem Biophys Res Commun 291: 987-989.

22) Muhibauer RC, Lozano A, Reinli A. 2002. Onion and a mixture of vegetables, salads and herbs affect bone resorption in the rat by a mechanism independent of their base excess. J Bone Miner Res 17: 1230-1236.

23) Mukherjee M, Das AS, Mitra S, Mitra C. 2004. Preven- tion of bone loss by oil extract of garlic (Allium sativum Linn.) in an ovariectomized rat model of osteoporosis. Phytother Res 18: 389-394.

24) Woo JT, Nakagawa H, Notoya M, Yonezawa T, Udagawa N, Lee IS, Ohnishi M, Hagiwara H, Nagai K. 2004. Quercetin suppresses bone resorption by inhibiting the differentiation and activation of osteoclasts. Biol Pharm Bull 27: 504-509.

25) Muhibauer RC, Lozano A, Palacio S, Reinli A, Felix R. 2003. Common herbs, essential oils and monoterpenes potently modulate bone metabolism. Bone 32: 372380.

26) Masuda $K$, Kawaguchi $T$, Koyama T, Nishimura $T$, Kawagishi H, Yazawa K. 2010. Osteoclast-forming suppressive compounds from Anoectochilus formosanus. Jpn J Comp Alternative Med 7: 121-124.

27) Lin CC, Hsu YF, Lin TC. 2001. Antioxidant and free radical scavenging effects of the tannins of Terminalia catappa L. Anticancer Res 21: 237-243.

28) Tanaka T, Nonaka GI, Nishioka I. 1986. Tannins and related compounds. XLII. Isolation and characterization of four new hydrolysable tannins, terflavins A and B, tergallagin and tercatain from the leaves of Terminalia catappa L. Chem Pharm Bull 34: 1039-1049.

29) Park EK, Kim MS, Lee SH, Kim KH, Park JY, Kim TH, Lee IS, Woo JT, Jung JC, Shin HI, Choi JY, Kim SY. 2004. Frosin, an ellagitannin, suppresses RANKL-induced osteoclast differentiation and function through inhibition of MAP kinase activation and actin ring formation. Biochem Biophys Res Commun 325: 1472-1480. 